\title{
CONTINUOUS STRUCTURAL MONITORING OF ADOBE BUILDINGS: SUMMARY OF A THREE YEARS EXPERIENCE IN PERU
}

\section{GIACOMO ZONNO ${ }^{1}$, RAFAEL AGUILAR ${ }^{1 *}$, RUBÉN BOROSCHEK ${ }^{2}$ AND PAULO B. LOURENÇO ${ }^{3}$}

${ }^{1}$ Department of Engineering, Pontificia Universidad Católica del Perú - PUCP, Av. Universitaria 1801, San Miguel, Lima 32, Peru e-mail: g.zonno@pucp.edu.pe, raguilar@pucp.pe (*corresponding author)

${ }^{2}$ University of Chile, Department of Civil Engineering, Av. Blanco Encalada 2002, Santiago, Región Metropolitana, Chile e-mail: rborosch@ing.uchile.cl

${ }^{3}$ University of Minho, ISISE, Department of Civil Engineering, Campus de Azurém 4800 - 058 Guimarães, Portugal e-mail: pbl@civil.uminho.pt

Keywords: Historic Structure, Andean Church, Structural Monitoring, Environmental Monitoring, Correlation Analysis

\begin{abstract}
The paper describes in detail the application of a vibration-based structural health monitoring system installed in the "San Pedro Apostol" church of Andahuaylillas located in Cusco (Peru), a 16th century adobe church considered a representative example of South America baroque architecture. The results of three years of long-term vibration and temperature and humidity monitoring program are reported in detail in the paper, with a focus on the long-term and short-term correlations between natural frequencies and environmental parameters. The results demonstrate that an accurate estimation of the first eight frequencies in the range 2-6 Hz is possible in the case of complex adobe structure and the existence of an annual cyclical behavior of the natural frequencies with a clear correspondence with the changes in environmental conditions due to seasonal influences. The performed correlations of ambient conditions and structural parameters confirmed the presence of different timescales and their not negligible influence in the case of a vibration-based structural health monitoring assessment of adobe systems with large thermal inertia large thermal inertia.
\end{abstract}

\section{INTRODUCTION}

Adobe has a very significant place in the field of civil construction materials. Different types of structures were made over the centuries and in various parts of the World with this material due to its attractive characteristics such as low cost, local availability, the possibility to be self/owner-made, good thermal insulation and acoustic properties [1]. The use of sun-dried 
blocks dates bakes to $8000 \mathrm{BCE}$ and, in more recent times, it was estimated that around $30 \%$ of the world population lives in earthen constructions [2]. Nowadays, a wide range of earth buildings can be found in Europe, Asia, Middle East, Africa and America. In particular, adobe buildings are extensively diffused in Latin America, and in Peru where cultural heritage and archaeological sites made of this material are a fundamental part of its intellectual richness and cultural diversity. The sacred city of Caral (2000 BCE), the complexes of "Huaca del Sol" and "Huaca de la Luna" (100-800 CE), the pre-Colombian city of Chan-Chan (850-1476 CE) are some of the numerous examples of Peruvian earthen monuments [3].

Unfortunately, these structures require a special attention and investigation due to the high vulnerability of the adobe heritage buildings affected by anthropological factors (such as lack of maintenance, inappropriate use and traffic vibrations), natural factors (such as earthquakes, tsunami and environment conditions) and intrinsic factors (such as aging of the materials and the low tensile strength and brittle behaviour of the adobe) [4]. Modern tools were developed to assess existing buildings and reduce their vulnerability. Within the available tools, vibrationbased structural health monitoring (VSHM) is finding an increasing use in the preservation and conservation of historical constructions such as bell towers [5], stone masonry churches [6] and buildings [7] due to its low invasiveness, the possibility to increase of the level of knowledge of structural system with high accuracy and the possibility of check the health state of the structures [8]. The structural health assessment of existing buildings by vibration-based monitoring systems is a challenge task because the influence of the environmental parameters (mainly temperature and humidity) can lead a variation of the boundary conditions [9], in the system stiffness [10] and others, masking variations duc to structural danages. In the case of
earthen existing buildings, the authors how in [11-12] how thermohygrometric variations can
produce significative changes in natural frequencies at long and shoyt scales because the
environmental parameters are time-dependent and non-uniforn quantities.
The paper reports the results obtained with the three years of vSHM of masterpiec of the
Peruvian cultural heritage earthen building, the "San Pedro Apostol" church of the

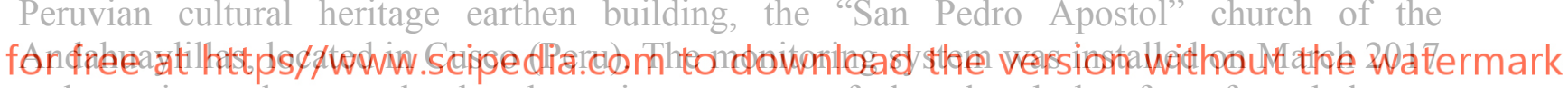
and continuously records the dynamic response of the church by four force-balances accelerometers and the environmental conditions by temperature and humidity sensors. The paper in Section 2 describes the cases study and the carried-out monitoring systems, in Section 3 describes the obtained results and Section 4 concludes the paper.

\section{THE "SAN PEDRO APOSTOL" CHURCH OF ANDAHUAYLILLAS}

\subsection{Description of the case study}

The "San Pedro Apostol" church is located in the main square of the Andahuaylillas, a village close to the Cusco city, in southeastern Peru, in the Andean region and it is considered the most emblematic colonial adobe church of South America (Fig. 1a). The church was built by Jesuit in the $16^{\text {th }}$ century and is known as the "Sistine Chapel of Latin America" for its inestimable mural painting (Fig. 1b). The church covers an area of 61 x $27 \mathrm{~m}$ (Fig. 1c), with a main nave of $58 \times 12 \mathrm{~m}$ and a height of $10 \mathrm{~m}$, and it is connected directly to the baptistery, the bell tower, two later chapels and, by a triumphal arch, to the presbytery (Fig. 1d). The adobe walls have a variable thickness from $1.10 \mathrm{~m}$ to $2.00 \mathrm{~m}$ and a stone masonry foundation with a height of $1.5 \mathrm{~m}$. The longitudinal walls of the nave are connected by wooden tie-beams and 
steel tie-rods and the roofing system is composed by a "A-shape" trusses of timber elements [13].
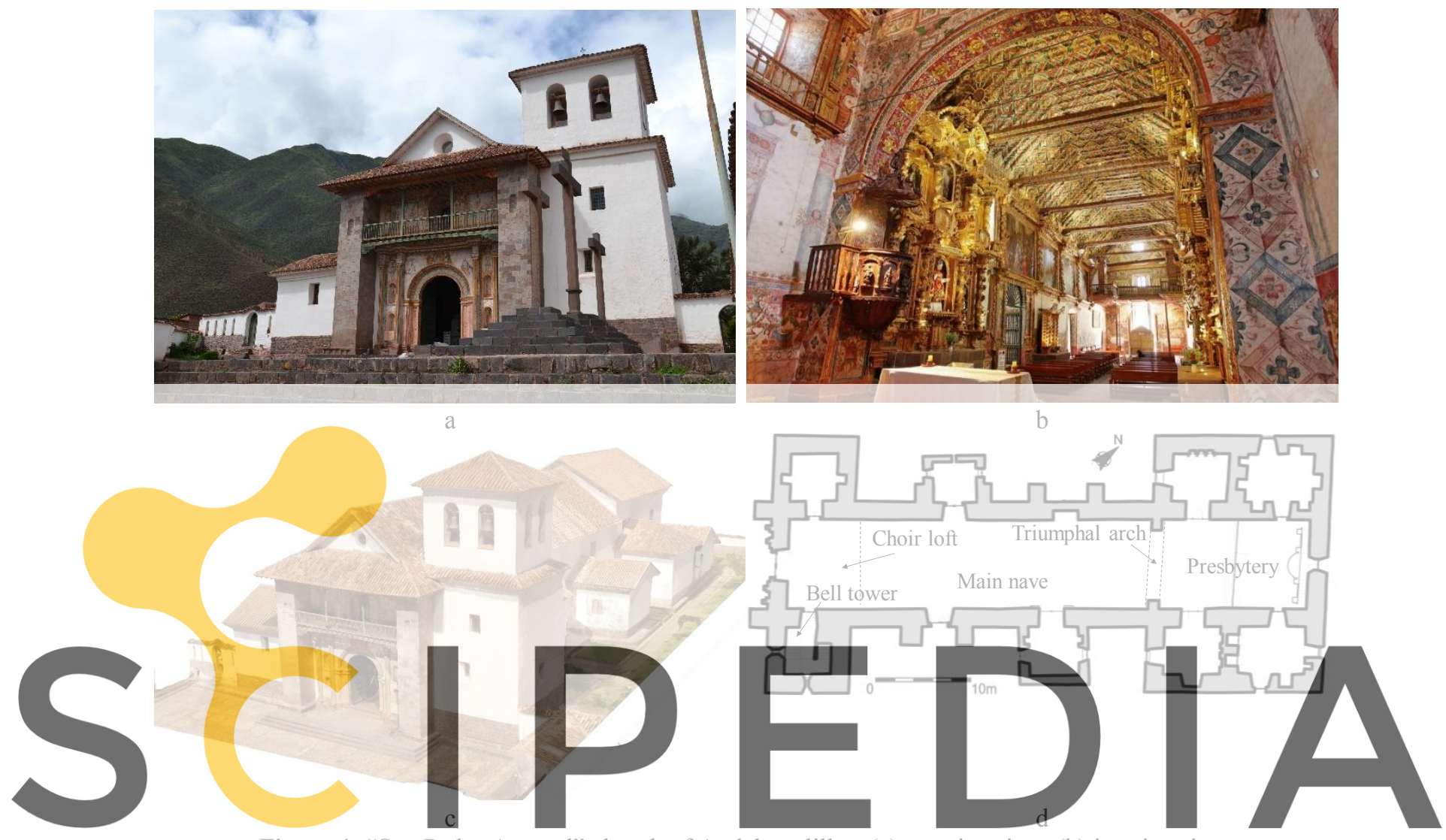

Figure 1: "San Pedro Apostol" church of Andahuaylillas: (a) exterior view, (b) interior view,

Register for free at https//wWW reconstruction, and (d) plat view at the height of the base.

\subsection{Description of the monitoring system}

For the importance of the building and to increase the knowledge about the dynamic and thermohygrometric behaviour of the structure, a remote and continuous dynamic monitoring system and an environmental monitoring system were installed on the church on March 2017. The implemented monitoring systems are summarized in Fig. 2, and consist: (i) local acquisition and storage of the raw data (dynamic and environmental data), (ii) transmission of the raw data by a $4 \mathrm{~g}$ data plan to the central monitoring station, (iii) reception and storage of data, (iv) processing of raw data, and (v) publishing the results in a web platform using a cloud engine. For the processing of the dynamic raw data (stage iv of the monitoring system), an automatic processing tool was developed and tested in [14]. In particular, the developed tool is able to identify automatically the frequencies, mode shapes and damping values of the structure through four main steps: (a) digital signal pre-processing of the dynamic data; (b) application of the SSI-Data method to obtain the stabilization diagram; (c) filtering of the stabilization diagram with the application of hard and soft validation criteria; (c) automatic detection of the modal parameters using hierarchical clustering approach and automatic thresholds; and (d) the 
application of an adaptive modal tracking for a final cleaning of the dynamic results (see more details in [14]).

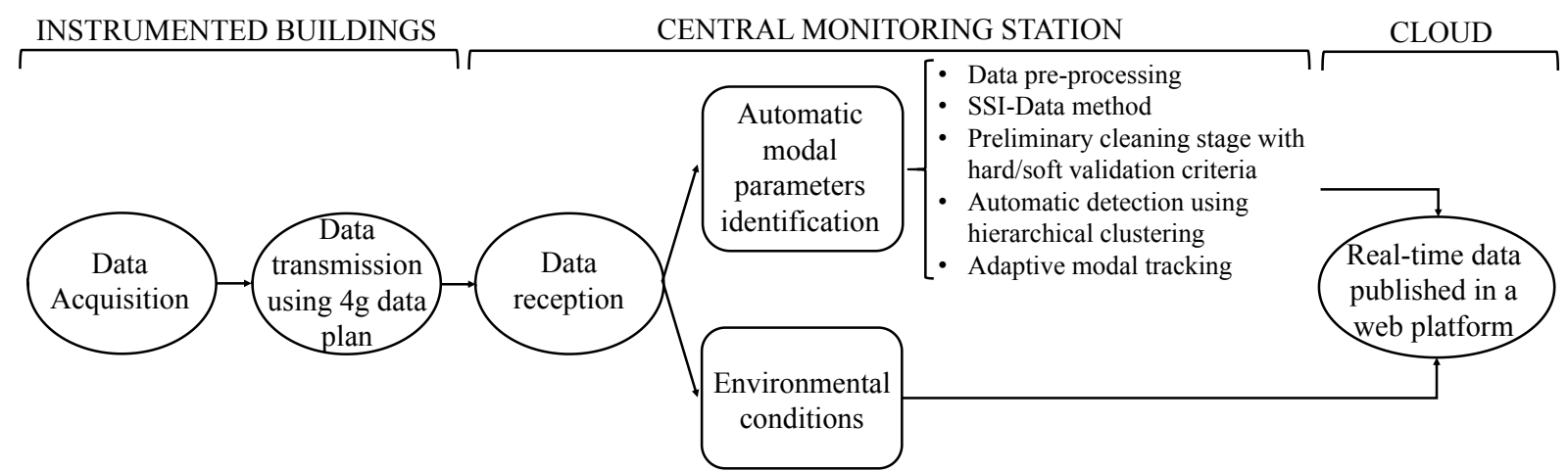

Figure 2: Overview of the structural monitoring system implemented in the "San Pedro Apostol" church.

Within this context, the implemented dynamic monitoring system consists of a Kinemetrics Obsidian 8x [15], a data acquisition unit with a capacity of 8-channels and 24 bits of resolution (Fig. 3f) and four uniaxial force balance accelerometers Episensor ES-U2 [16] with a bandwidth range from DC to $200 \mathrm{~Hz}$, a dynamic range of $155 \mathrm{~dB}+$, a sensitivity of $10 \mathrm{~V} / \mathrm{g}$, and an operating temperature range from $-20{ }^{\circ} \mathrm{C}$ to $70{ }^{\circ} \mathrm{C}$ (Fig. 3c). To generate a stable power supply, an external battery (Fig. 3h) with a voltage regulator (Fig. 3i), and a battery charging-maintainer (Fig. 3g) are incorporated. The accelerometers are located at the ton height of the north and south nave walls (see F nave. The data acquisition parameters are set at a of 900 s for each event and with a time recurre The envirommental monitoring system used to perform the of the external and internal temperature and humidity is composed by a HOBO RX-3000 Data

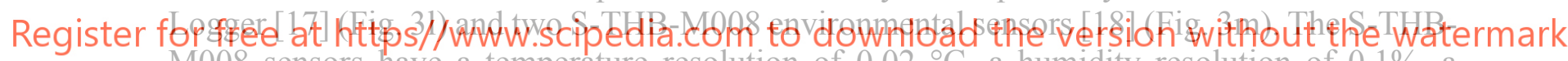
M008 sensors have a temperature resolution of $0.02^{\circ} \mathrm{C}$, a humidity resolution of $0.1 \%$, a temperature measurement range between $-40^{\circ} \mathrm{C}$ and $75^{\circ} \mathrm{C}$, and a humidity measurement range between 0 and $100 \%$. The environmental sensors are placed outside ( $\mathrm{T}_{\text {ext }}$ and $\mathrm{H}_{\text {ext }}$ in Fig. 3a) and near the entrance of the church $\left(\mathrm{T}_{\text {int }}\right.$ and $\mathrm{H}_{\text {int }}$ in Fig. 3a) to record the internal and external temperature and humidity. The environmental parameters are recorded with a time recurrence of one hour. For remote communication, the Obsidian 8x, and the HOBO RX-3000 Data Logger were connected by Ethernet cables to a TP-Link modem with a phone data plan (Fig. 3d) to automatically send the recorded information to the central monitoring station using a safe File Transfer Protocol (FTP). During the entire monitoring period more than 23000 raw data was sent from the instrumented building to the central station. 
a
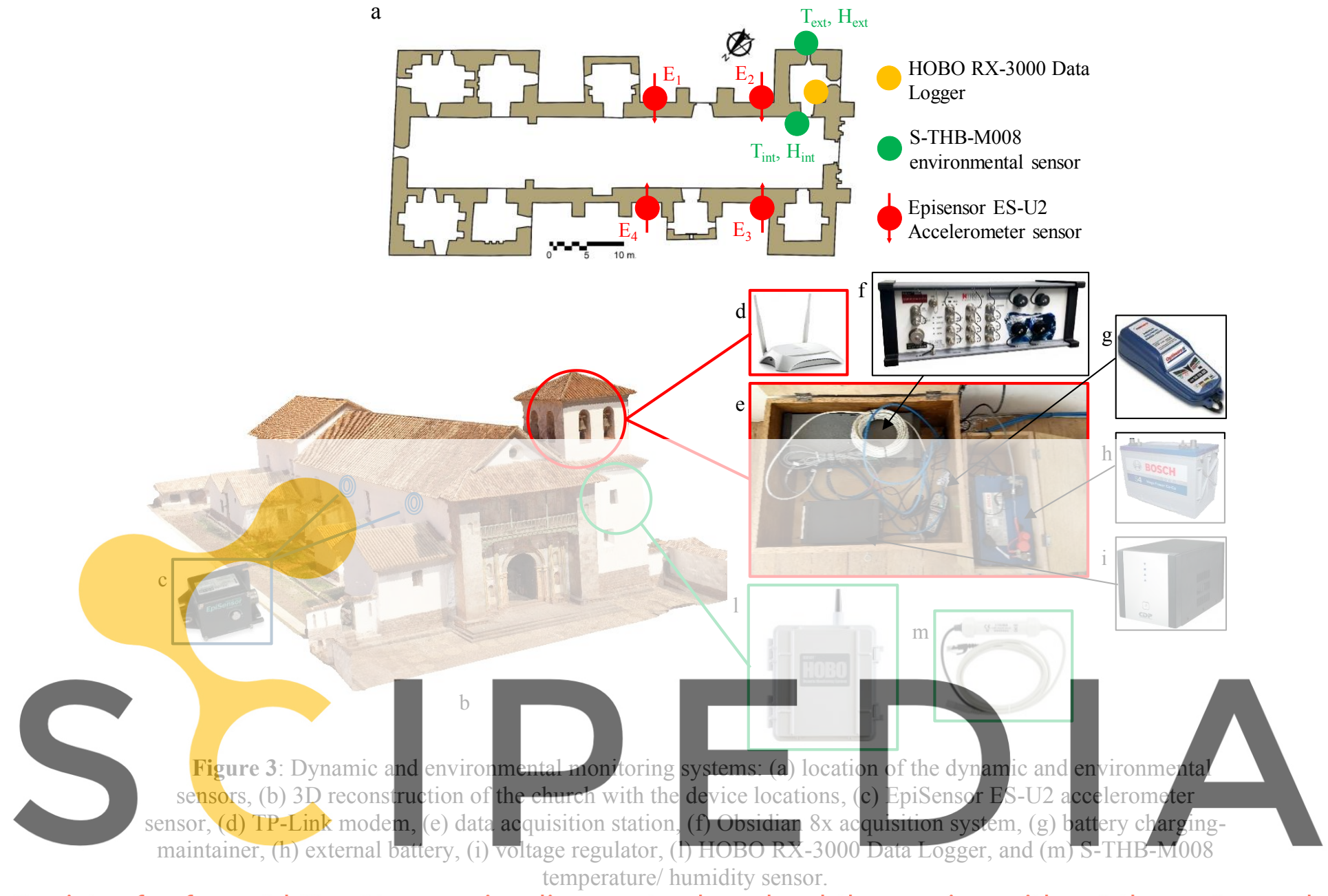

Register for free at https//www.scipedia.com to download the version without the watermark

\section{MONITORING SYSTEMS RESULTS}

The analysis of the recorded ambient vibration data was performed, and the results are presented in Fig. 4. As shown, the first eight frequencies of the adobe church were clearly detected in the range $2 \mathrm{~Hz}$ and $7 \mathrm{~Hz}$. As shown, the results indicate a seasonal influence during the monitoring period. Lower frequency values were reached during colder months (between June and September), while higher values in the summer months (between December and March). An irregular behavior was detected close to November 2018 with a local decrease of all the identified frequencies. 


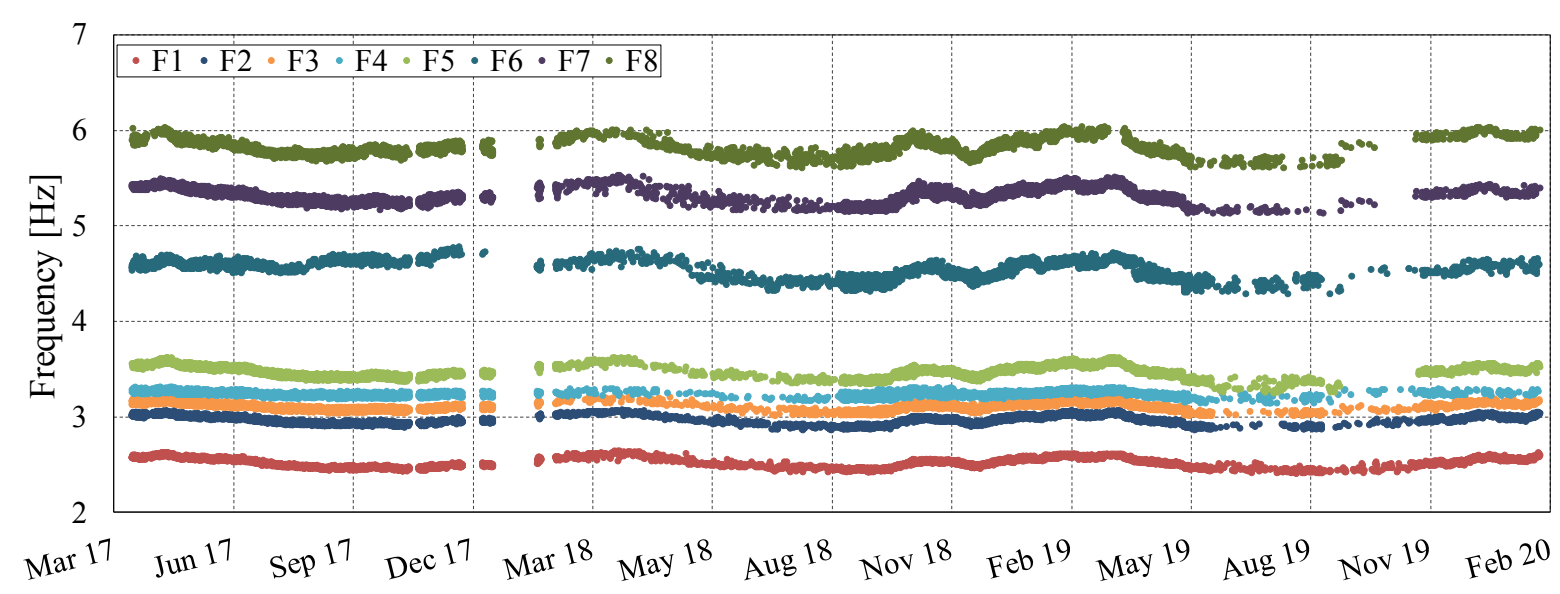

Figure 4: Time evolution of the first eight natural frequencies of the "San Pedro Apostol" church from March 2017 to November 2019.

The results of the ambient temperature and relative humidity evolution are shown in Fig. 5. The external ambient temperature $\left(\mathrm{T}_{\text {ext }}\right.$ ) exhibits a not clear seasonal trend of the data with higher daily variations in the summer period and lower in the winter one (Fig. 5a), reaching a maximum value of $28^{\circ} \mathrm{C}$ and a minimum value of $5^{\circ} \mathrm{C}$ during the monitoring period. On the contrary, the internal ambient temperature records $\left(\mathrm{T}_{\text {int }}\right)$ shows clear seasonal trends, with an increase of the values during the summer period and a decrease in the winter one (Fig. 5a). An

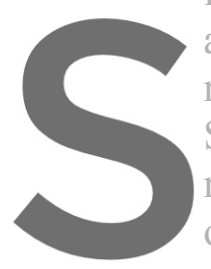
attenuation phenomeno records, reaching a maxi Similar attenuation between external and relative humidity (see th of Fig. 5b). The value
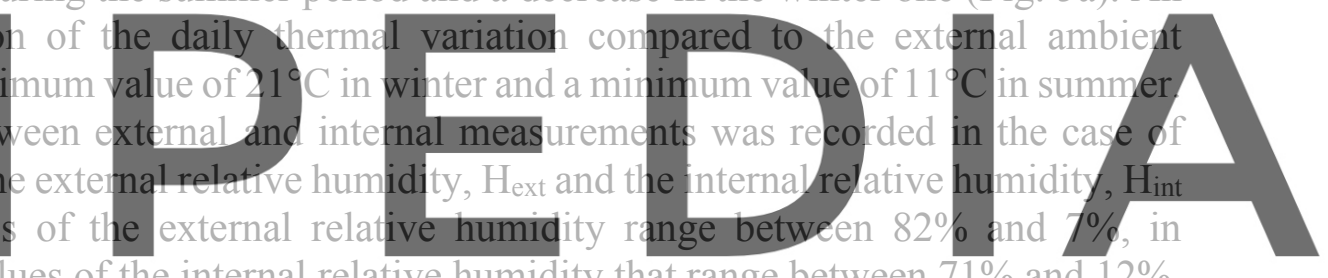
comparison with the values of the internal relative humidity that range between $71 \%$ and $12 \%$.

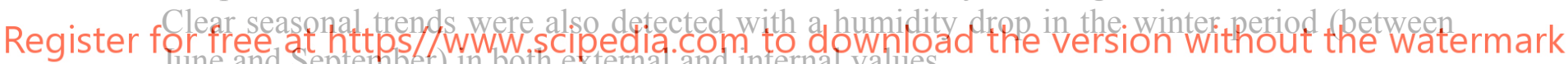
fune and Septembef) mboth externaland internal values.

Aiming at developing a single variable that integrates information of ambient temperature and relative humidity, the external and internal absolute humidity $\left(\mathrm{AbsH}_{\text {ext }}\right.$ and $\mathrm{AbsH}_{\text {int }}$, respectively) were calculated to achieve a better understanding of the effects of thermohygrometric parameters on the natural frequencies of the adobe church (see more details of how this variable is calculated in [13]). In particular, $\mathrm{AbsH}_{\text {ext }}$ and $\mathrm{AbsH}_{\text {int }}$ were calculated using the recorded data of $\mathrm{T}_{\text {ext }} / \mathrm{H}_{\text {ext }}$, and $\mathrm{T}_{\text {int }} / \mathrm{H}_{\text {int }}$ sensors, respectively, and they represent the amount of water vapor in the external and internal air of the church. The results of the calculated absolute humidity values in the entire monitoring period are showed in Fig. 5c. A clear seasonal decrease (from $10 \mathrm{~g} / \mathrm{m}^{3}$ to $2 \mathrm{~g} / \mathrm{m}^{3}$ ) was recorded for both parameters in the winter period, with an irregular behavior detected close to November 2018, with a clear similarity of the time evolution of the identified frequencies. Furthermore, high capacity to reduce the variation between the external and internal measurements is shown by this calculated parameter. 

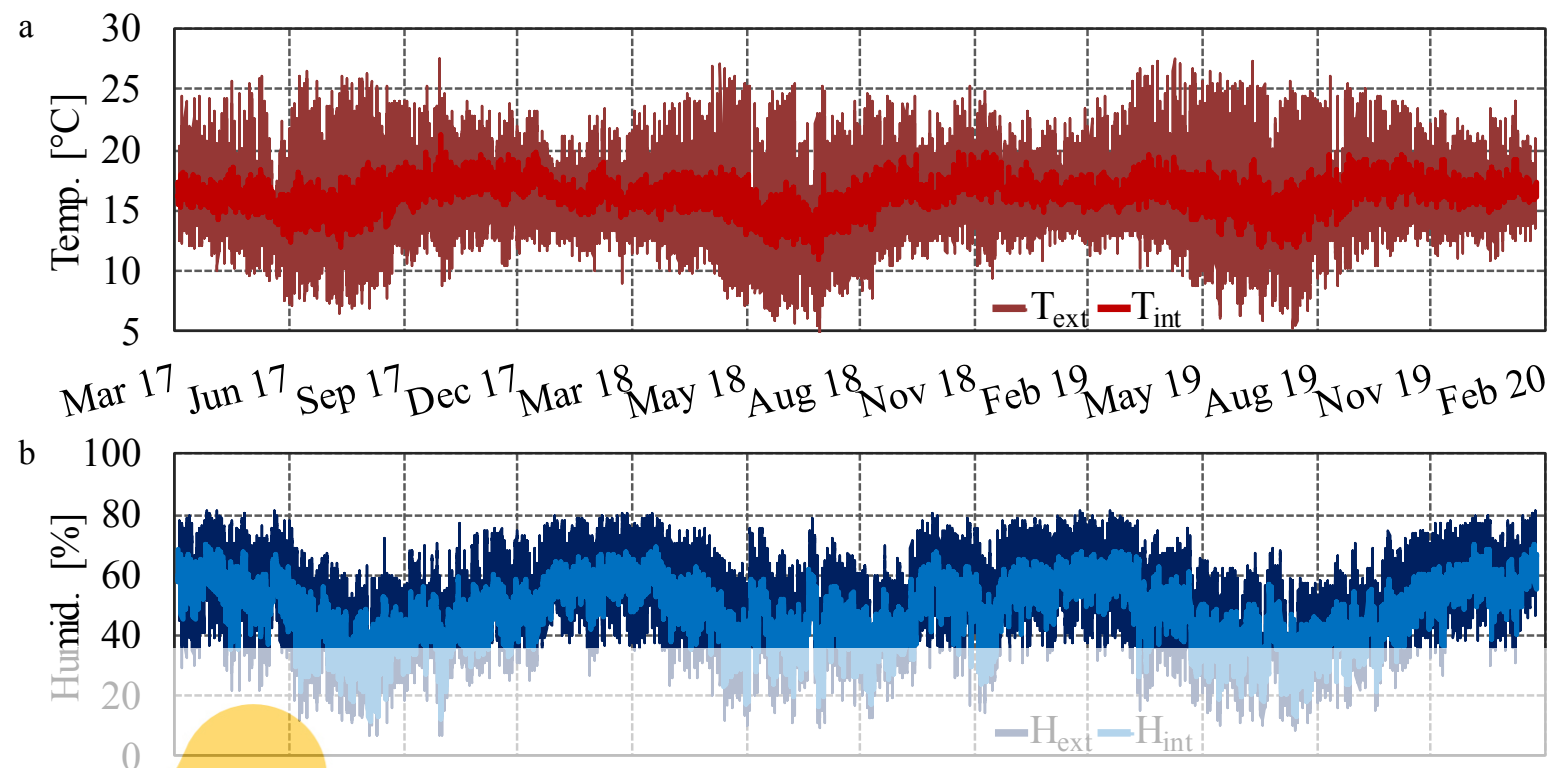

Mar 17 Jun 17 Sep 17 Dec ${ }^{17}$ Mar 18 May ${ }^{18}$ Aug 18 Nov 18 Feb ${ }^{19}$ May ${ }^{19}$ Aug 19 Nov ${ }^{19}$ Eeb 20

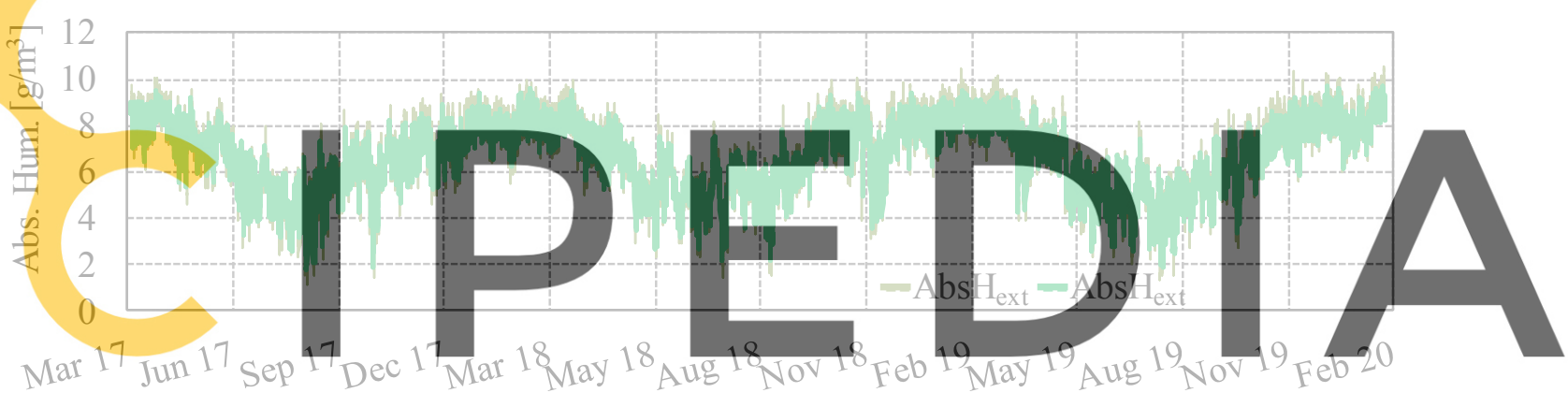

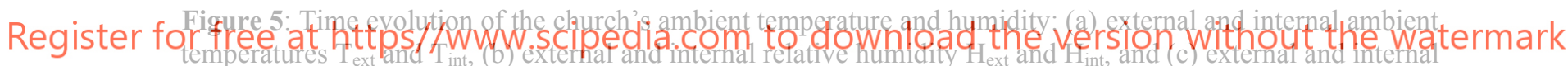
absolute humidity $\mathrm{AbsH}_{\mathrm{ext}}$ and $\mathrm{AbsH}_{\text {int }}$.

\section{ANALYSIS OF THE INFLUENCE OF AMBIENT CONDITIONS IN THE DYNAMIC STRUCTURAL BEHAVIOUR}

A detailed study was performed between the first frequency of the "San Pedro Apostol" church and the external ambient humidity. The external ambient humidity was selected as parameter for comparison due to:

(a) the absolute humidity has demonstrated to be an effective parameter for performing correlation analyses [12];

(b) $t$ absolute humidity is less affected by the thermal inertia of the adobe, demonstrated by a higher correlation between external and internal environmental measurements;

(c) in most structural monitoring, the external environmental parameters are easier to obtain. Furthermore, in sake of brevity, in the present paper only the results of the first frequency will be described in detail.

Fig. 6 shows the correlation distributions of the first frequency with the external absolute 
humidity corresponding to the entire monitoring period. Aiming at analyzing the influence of the environmental parameters on the frequency with different timescales, the raw data was filtered by averages with different timescale. In particular, Fig. 6a shows the correlation distribution obtained by the raw data. Fig. $6 \mathrm{~b}$ shows the correlation distribution obtained by filtering the raw data with a daily average (the mathematical average was carried out with the 24 data recorded in one day). Finally, Fig. 6c, Fig. 6d, and Fig. 6e show the correlation distribution obtained by filtering the raw data by averaging the data of 7 days, 15 days and 30 days, respectively.

The results show that the correlation coefficients between the raw data of the first frequency and external ambient humidity are almost good $\left(\mathrm{R}^{2}=0.35\right)$ with a positive trend. The results of the correlation distribution with the daily average filtered data show a higher value of correlation coefficient $\left(\mathrm{R}^{2}=0.47\right)$ with a clearer positive trend. The results improve with the 7 days average filter, reaching a correlation coefficient of 0.58 . Finally, with the 15 days average filter and the 30 days average filter, there is a slight improvement of the results, reaching a correlation coefficient of 0.65 .
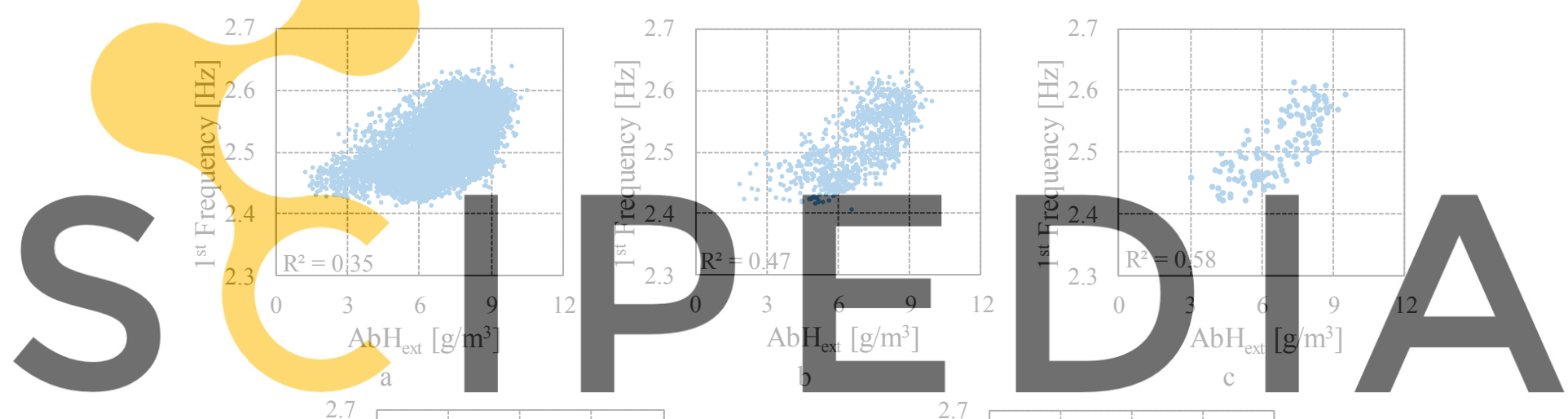

Register for free athattps/Awww.scipedia.com to down
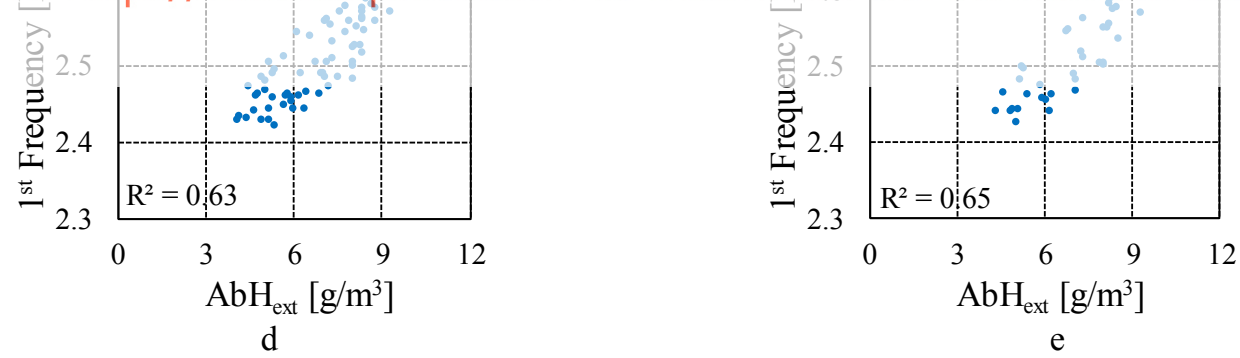

Figure 6: Correlation coefficients distribution between the first natural frequency and external absolute humidity: (a) raw data, (b) data filtered by a daily average, (c) data filtered by a 7 days average, (d) data filtered by a 15 days average, and (e) data filtered by a 30 days average.

\section{CONCLUSIONS}

The paper reports the results of almost three years of environmental and dynamic monitoring of the emblematic "San Pedro Apostol" adobe church of Andahuaylillas, Cusco (Peru). The results show on one side the influence of the adobe structure on the diffusion of temperature and humidity inside the church, and on the other side, the influence of the environmental 
parameters on the dynamic response of the same structure.

The comparison between the evolution of the internal and external environmental conditions shows a clear attenuation of the internal measurements, confirming the influence of the thermal inertia of this type of buildings, mitigating the extreme ambient climatic conditions recorded outside the church.

The analysis of the influence of the environmental parameters on the dynamic response of the structure show an annual cyclical behavior in the time evolution of the first eight frequencies of the church, with a clear similarity with the time evolution of the environmental parameters (long-term analysis). Furthermore, a medium-term and a short-term analyses were performed with the calculated external absolute humidity, and improved results were attained when the daily variation, the 7 days variation, the 15 days variation and the 30 day variation were removed from the original raw data of natural frequencies and environmental parameters

The successful implementation of an environmental and dynamic monitoring system in a $16^{\text {th }}$ century historical adobe church and the obtained results about the relevant role of the environmental parameters at different time scales in the dynamic response of adobe systems make the vibration-based structural health monitoring system a useful tool for the conservation and protection of the cultural heritage buildings.

\section{REFERENCES}
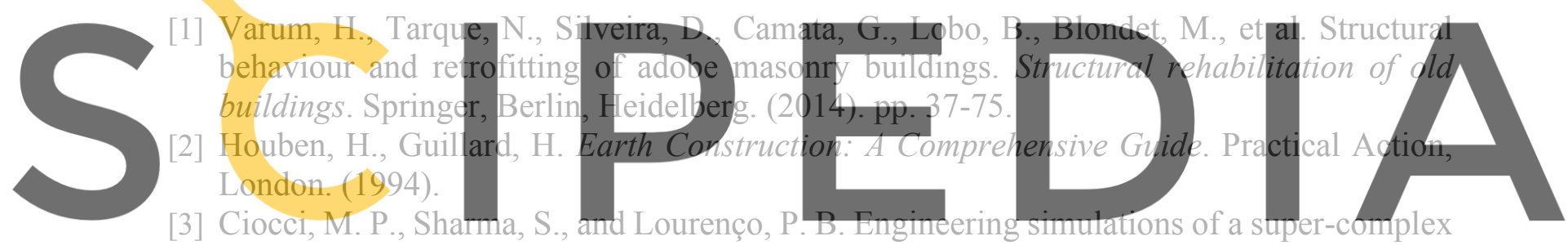

cultural heritage building: Ica Cathedral in Peru. Meccanica. (2018). 53(7): 1931-1958

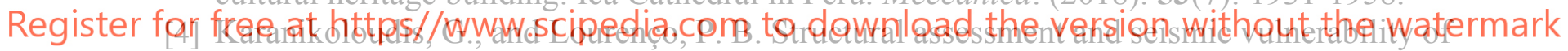

earthen historic structures. Application of sophisticated numerical and simple analytical models. Eng. Struc. (2018). 160: 488-509.

[5] Saisi, A., C. Gentile, and A. Ruccolo. Continuous monitoring of a challenging heritage tower in Monza, Italy. J. Civ. Struct. Health Monit. (2018). 8(1): 77-90.

[6] Elyamani, A., O. Caselles, P. Roca, and J. Clapes. Dynamic investigation of a large historical cathedral. Struct. Control Hlth (2017). 24(3): e1885.

[7] Lorenzoni, F., F. Casarin, M. Caldon, K. Islami, and C. Modena. Uncertainty quantification in structural health monitoring: Applications on cultural heritage buildings. Mech. Syst. Signal Pr. (2016). 66:268-81.

[8] Ramos, L., Marques, L., Lourenço, P. B., De Roeck, G., Campos-Costa, A., Roque, J. Monitoring historical masonry structures with operational modal analysis: two case studies. Mech. Syst. Signal Pr. (2010), 24: 1291-1305.

[9] Ubertini, F., C. Gentile, and A. L. Materazzi. Automated modal identification in operational conditions and its application to bridges. Eng. Struc. (2013). 46:264-78.

[10] Maeck, J., B. Peeters, and G. De Roeck. Damage identification on the Z24 bridge using vibration monitoring. Smart Mater. Struct. (2001). 10(3):512. 
[11] Zonno, G., R. Aguilar, R. Boroschek, and P. B. Lourenço. Experimental analysis of the thermohygrometric effects on the dynamic behavior of adobe systems. Constr. Build. Mater. (2019). 208:158-74.

[12] Zonno, G., Aguilar, R., Boroschek, R., and Lourenço, P. B. Environmental and ambient vibration monitoring of historical adobe buildings: applications in emblematic Andean churches. Int. J. Archit. Herit. (2019). https://doi.org/10.1080/15583058.2019.1653402

[13] Zonno, G., Aguilar, R., Boroschek, R., and Lourenço, P. B. Analysis of the long and short-term effects of temperature and humidity on the structural properties of adobe buildings using continuous monitoring. Eng. Struc. (2019). 196: 109299.

[14] Zonno, G., Aguilar, R., Boroschek, R., and Lourenço, P. B. Automated long-term dynamic monitoring using hierarchical clustering and adaptive modal tracking: validation and applications. J. Civ. Struct. Health Monit. (2018). 8(5): 791-808.

[15] KINEMETRICS. (2019). Obsidian 8x multichannel seismic recorder. https://kinemetrics.com.

[16] KINEMETRICS. (2019). EpiSensor ES-U2 uniaxial episensor accelerometer. https://kinemetrics.com.

[17] ONSET. (2019). HOBO RX3000 remote monitoring station data logger. http://www.onsetcomp.com.

[18] ONSET. (2019). S-THB-M008 temperature/relative humidity smart sensor. http://www.onsetcomp.com.
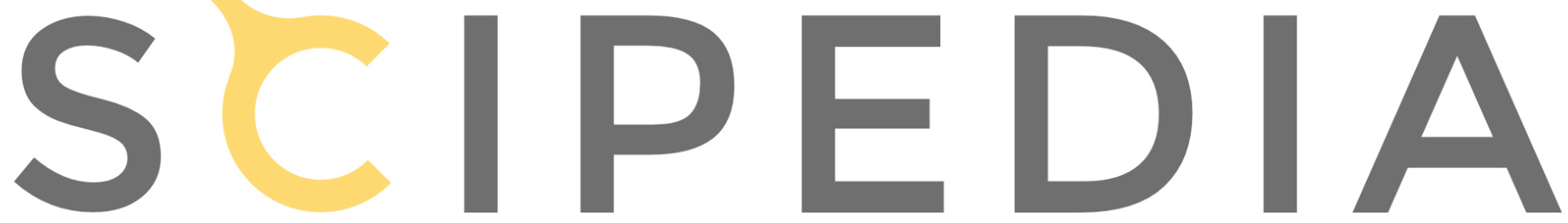

Register for free at https//www.scipedia.com to download the version without the watermark 